\title{
Análisis de recursos patrimoniales como fuente de productos turísticos en Caibarién.
}

\section{Analysis of heritage resources as a source of tourism products in Caibarién.}

Lic. Arnaldo Rojas López. ${ }^{1}$, Lic. Dailén Abreu Rodríguez. ${ }^{2}$ \& MSc. Daikel Adriano Abreu Rodríguez. ${ }^{3}$

\section{Resumen.}

El turismo se ha convertido en una de las actividades de mayor atracción en el mundo, con particular atención a su dimensión sociocultural. En el presente estudio se diagnostican los atractivos histórico-culturales de la Ciudad de Caibarién como producto urbano patrimonial de oferta complementaria al desarrollo del destino turístico Cayos de Villa Clara. Para esto se elabora un inventario de los atractivos histórico- culturales de la Ciudad de Caibarién; así como una fundamentación de la historia, atendiendo al proceso de formación y desarrollo del turismo, a partir de una breve caracterización del municipio. La investigación constituye un estudio actualizado del patrimonio turístico de la ciudad, el cual permite poner sus atractivos históricos culturales como un futuro producto turístico, por lo que representa una fuente de consulta para cualquier trabajo que se realice sobre el tema.

Palabras claves: patrimonio, producto turístico, inventario turístico.

\section{Abstract.}

Tourism has become one of the most attractive activities in the world, with particular attention to its socio-cultural dimension. In the present study, the historic-cultural attractions of the City of Caibarién are diagnosed as an urban patrimonial product of complementary offer to the development of Villa Clara Cays tourist destination. For this reason, an inventory of the historical-cultural attractions of the City of Caibarién is made; as well as a foundation of the history, taking into account the process of formation and

\footnotetext{
${ }^{1}$ Trabajador por cuenta propia. rojaslopezarnaldo@gmail.com

${ }^{2}$ Empresa Extrahotelera Palmares, Ministerio del Turismo, dailenar@nauta.cu

${ }^{3}$ Universidad de la Habana, Ministerio de Educación Superior, daikel_abreu@ftur.uh.cu
} 
development of the tourism, from a brief characterization of the municipality. The investigation constitutes an updated study of the tourist heritage of the city, which lets put its cultural historical attractions as a future tourist product, so it represents a source of consultation for any work that is carried out on the subject.

Keywords: heritage, tourism product, tourist inventory.

\section{Introducción.}

La actividad turística es considerada una de las primeras ramas de la economía de muchos países, aportando grandes ingresos a su Producto Interno Bruto. De allí que todo desarrollo turístico precise de una adecuada estrategia de desarrollo integrado, porque el turismo está relacionado de forma estructural con la mayoría de los sectores socioeconómicos (Roca, 2014).

Por su parte, los efectos de la globalización hacen que surja la necesidad de nuevas formas de incentivar el desarrollo con un nuevo clima organizacional e institucional que permita la participación local de todos los agentes y sujetos económicos (Quintero \& Gallardo, 2018).

Como actividad económica y social, es una de las vías que puede tomar una comunidad para su desarrollo local, integrando su destino, recursos, atracciones, activos y la suma de sus actores. Es importante establecer, prioritariamente, en términos de desarrollo turístico, una planificación participativa estratégica, apoyada en proyectos nacidos de la conciencia y reconocimiento del papel de los actores locales. (Domínguez Junco, Rodríguez Crespo, \& Fadul Franco, 2017). Se basa, además, en un mayor protagonismo del gobierno local en la gestión económica. A él corresponde decidir y administrar, de manera colegiada, el destino del dinero recaudado, de modo que este se revierta en mayores progresos para el territorio (Pérez F. , 2013).

El papel de la gestión de destinos es administrar y apoyar la integración de diferentes recursos, actividades y agentes involucrados a través de políticas y medidas apropiadas. Conlleva por tanto competencias tanto gubernamentales en materia de toma de decisiones como funcionales (planificación, organización y control de actividades empresariales), que normalmente deberían incumbir al sector público (Manente, 2014). Desarrollo Local es un paradigma de desarrollo reciente, de naturaleza compleja y multidimensional, que actúa a nivel político, psico-sociocultural, económico y ambiental de un territorio, buscando potenciar las condiciones endógenas a partir de sus actores sociales, para lograr mayor sostenibilidad, productividad y equidad en su desarrollo (Couto, 2006).

El turismo y el desarrollo local son estrategias de desarrollo que están en función del potencial territorial y de la riqueza natural, cultural y social. El requerimiento principal para el impulso del turismo a través de la labor municipal es la toma de conciencia, por parte de las autoridades locales, de la importancia del turismo en la generación de beneficios para su localidad.

La (UNESCO, 2001) define que el patrimonio cultural lo constituyen todos aquellos elementos culturales, tangibles e intangibles que son heredados o creados recientemente, 
es un recurso turístico, lo cual se transforma en argumento para recuperarlo y protegerlo, pues es un factor de dinamización y potenciación del desarrollo socioeconómico local y regional.

Incluso las más antiguas definiciones de turismo, según (Morangues, 2006); nos pueden ofrecer tópicos sobre aspectos relevantes de su relación con la cultura, ya que se hace indisociable el turismo de la cultura; en todo caso, no se entendería la misma génesis del turismo sin implicaciones culturales significativas.

El turismo cultural se encuentra profundamente centrado en la oferta monumental más importante, con el objetivo fundamental de adaptar los recursos turísticos a las demandas del turismo individual, concediendo un papel esencial a la oferta complementaria. Según (Osácar, 2003); la concentración del patrimonio cultural constituye la característica definitoria de las ciudades históricas y la base de su atractivo como destinos turísticos. El patrimonio y la motivación cultural están en la base misma del fenómeno turístico.

Un Producto Turístico Cultural Integrado lleva implícito todas aquellas muestras vivas de la creatividad humana que están latentes aún en la memoria y en los nuevos caminos por andar. Es esa mezcla de la salvaguarda de los valores patrimoniales culturales más auténticos y de arraigo popular de un pueblo (Yibo, 2009).

El patrimonio cultural se ha convertido en un componente esencial del desarrollo turístico de Cuba, por lo cual en la provincia de Villa Clara se exponen aún a pesar del tiempo transcurrido elementos constitutivos fundacionales, que componen el amplio arsenal patrimonial (Ausina Díaz, 2014).

En Cuba la Agencia de Viajes Paradiso es la responsable de la gestión del turismo especializado en la modalidad de Turismo Cultural, como promotora oficial de turismo cultural en nuestro país. Se pudo conocer en la Delegación del MINTUR de Villa Clara que existen varios productos turísticos culturales diseñados para promover el patrimonio cultural de las ciudades, pero en las propuestas que se comercializan, no se incluyen recursos patrimoniales culturales de gran envergadura en las ciudades. Los recursos intangibles como las leyendas de la ciudad y las costumbres tradicionales no están dentro de la agenda de los gestores de la actividad turística en el destino.

Observamos que la calidad constructiva y estética de los valores culturales de Caibarién existe un gran deterioro de los inmuebles patrimoniales y de sus tradiciones. Aún se carece de un producto que relacione todo el potencial de valores culturales tanto tangibles como intangibles. Por eso se hace necesario de la existencia de un producto que ofrezca elementos distintivos de la ciudad como son su fundación, los recursos históricos y culturales que han perdurado en el tiempo de la colonia y la república hasta la actualidad, y se logre satisfacer las necesidades de conocer el patrimonio vivo de Caibarién.

\section{Método.}

En la presente investigación se utilizó el "Procedimiento de Diagnóstico de los Recursos Turísticos Patrimoniales Tangibles e Intangibles”, de la MSc. Zeida Carvajal García; que sirve de guía científica permitiéndonos un conocimiento más profundo de los valores culturales patrimoniales de las ciudades. 
En el diagnóstico se utilizaron métodos como el análisis de documentos, observación y encuestas no estructuradas a personas que tienen mucha relación con la historia de la ciudad.

\section{Procedimiento de diagnóstico de los Recursos Turísticos Patrimoniales Tangibles e Intangibles.}

Fase 1: Objetivo: Diagnosticar las problemáticas en la utilización del Patrimonio Tangible e Intangible, como recurso turístico cultural para la proyección de un Producto Turístico Cultural Integrador en el destino turístico.

Técnicas a utilizar: Entrevista en Profundidad, Grupo Focal, Observación Participante.

Fase 1l: Objetivo: Estudio teórico del inventario de recursos culturales del Destino Turístico en:

- Investigaciones sobre el tema.

- Material bibliográfico.

Técnicas por utilizar: Estudio Documental.

Fase 11l: Objetivo: Estudio práctico del inventario de recursos patrimoniales culturales turísticos en el Destino Turístico en:

- Visita a espacios patrimoniales tangibles.

- Valoración de su estado constructivo y mantenimiento.

- Visitas a lugares que contienen el patrimonio intangible.

Técnicas a utilizar: Entrevistas en profundidad, Grupo Focal, Observación Participante.

Fase lV: Objetivo: Informe final del resultado diagnóstico para poseer una caracterización profunda del comportamiento de Recursos Turísticos Patrimoniales Tangibles e Intangibles del destino turístico.

Fuente: (Carvajal , 2013).

\section{Resultados y Discusión.}

Para elegir los lugares de alto valor patrimonial se utilizaron como bases investigaciones anteriores sobre el valor patrimonial de la Ciudad de Caibarién, para seleccionar los espacios más significativos de la localidad, donde (Estevez, 2006) realiza una lista del patrimonio tangible de la Ciudad de Caibarién según su valor histórico-cultural. Mediante entrevistas realizadas a especialistas de patrimonio se pudo constatar los sitios más significativos, que podrían mostrarse como atractivos turísticos.

\section{Recursos tangibles.}

1. Edificio Delgado: Ubicado en la esquina de calle \# 10 y avenida \# 7, fue fundada en el año 1926 por la familia Delgado y constituye un fiel representante del eclecticismo en la localidad. En la misma radicó la oficina de correos de la ciudad. También vivieron en ella grandes personalidades de la localidad como Manolín Álvarez y Carmen Sánchez Boffil. Este edificio constituye una valiosa representación arquitectónica de la época.

Cuenta con dos plantas, en sus inicios en la primera planta se encontraba las oficinas de 
correos de la ciudad y la casa de su administrador, siendo la segunda planta destinada a las actividades de la "Sociedad de Caballeros Católicos" y existían dos casas de viviendas, una habitada por Manolín Álvarez donde se realizaron varias transmisiones de radio, hijo ilustres de la ciudad reconocido por la población como el pionero de la radio en Caibarién y la otra habitada por la también reconocida maestra Carmen Sánchez Boffil. Su construcción se destaca con la utilización, por primera vez de losas antiresbalables en los pisos de su portal, siendo además meritorio destacar que las mismas se produjeron en la fábrica de mosaicos de la ciudad. La edificación era reconocida en aquel entonces por los torneos de tenis de campo que se realizaban en su azotea, la cual reunía todas las condiciones para ello desde el punto de vista de longitud del área y además hoy se pueden apreciar los soportes que se utilizaban para colocar la net para los mencionados partidos (Inventario de Construcciones Conmemorativas del Ministerio de Cultura).

2. Edificio Art-Decó: Edificio situado en la esquina de la calle Cuba y avenida Máximo Gómez. El inmueble constituye un magnífico exponente del ARTDECO, es uno de los exponentes más hermoso y bello de este tipo de arquitectura en la provincia de Villa Clara. Construido en 1935 por el Arquitecto Herminio Laurderman, de ladrillos y losas de entre suelos y cubierta de hormigón planas, presenta dos niveles con una planta rectangular con patios interiores, en el primer piso se sitúan servicios y en el segundo, viviendas.

Su fachada muestra un portal de granito corrido, característico de los elementos urbanos de la ciudad; en el primer nivel grandes pilares que sobresalen de la cubierta escalonadamente con una terminación en líneas rectas y elementos cilíndricos adosados al pretil incorporado al parámetro exterior prácticamente sin diferenciarse el uno del otro. El mismo rompe con la arquitectura predominante en la época, lo cual puede apreciarse con solamente detenerse y compararlo con las restantes construcciones que existen alrededor del parque, donde predomina el estilo ecléctico.

3. Iglesia Católica "La Purísima Concepción": Fue planificada por Don Estratón Bauza en 1834, de aquí que los pobladores de la época la llamaran "La Ermita de Bauza", en sus inicios era de madera y guano, no siendo hasta 1857 que se comienzan los trabajos para edificar el nuevo templo. El cual no contaba con la torre, no siendo hasta 1863 que se construye la misma que hoy en día apreciamos y al año siguiente se instaló el reloj de cuatro esferas, todo un acontecimiento para los tiempos, donado por el comerciante norteamericano H.R. Bischop. Se conoce que el primer bautizo se realizó en el año 1848. Templo uninave de mampuesto y tejas. Torre con campanario de 3 secciones terminada en pirámide y con un reloj de 4 esferas en la sección superior. Techo de la nave de alfanjes con harmezuelo, tirante triple al centro, 2 parejas de tirante dobles a cada lado de este. Cuadrales esquineros, todos apoyados en mensuras, y una decorativa al centro del arco que conduce al presbiterio. Se le suprimió el retablo neoclásico de madera y el púlpito. Se le añadió un nicho al lado de la puerta de la derecha con arcos de medio punto y enmarcado en pilastra neoclásicas.

4. El Liceo: Ubicado en Máximo Gómez esquina con la calle Padre Varela, se encuentra dentro del Centro Histórico, a un costado del Parque "La Libertad". Insertado en el sector de mayor actividad cultural, social y económica de la ciudad, se integra al entorno circundante donde existe un predominio de la tipología constructiva de mampostería, 
alternándose edificios de una o de dos plantas, todo con elevado puntal y representativos del eclecticismo. Este edificio a partir de 1920 se convierte en "Liceo". Toma su aspecto actual de dos niveles el 26 de febrero de 1926 cuando queda constituida la Sociedad "Recreo de Artesanos".

Presenta un alto valor histórico y arquitectónico, ya que sus salas han sido testigos de numerosos e importantes acontecimientos, entre los que se destacan: visitas realizadas por figuras relevantes como Máximo Gómez, José Raúl Capablanca y el comandante Ernesto Guevara de la Serna.

5. Edificio de Gobierno: Ubicado en la avenida \# 7 entre calle Cuba y Padre Valera, esta pequeña edificación, comparada con las restantes del centro histórico de la ciudad, fue fundada en 1913 siendo representativa del eclecticismo formativo y destinada desde su inicio como casa de gobierno, además se encontraban en este mismo lugar la estación de bomberos de Caibarién, la cual contó con el primer carro bomba en Cuba, la policía, la casa socorro y la biblioteca de la ciudad. En la actualidad una parte del mismo funge como Gobierno Municipal y la otra pertenece a la Unidad de los Servicios Comunales (Inventario de Construcciones Conmemorativas del Ministerio de Cultura).

6. Parque temático de Locomotoras a Vapor: El museo del vapor constituye hoy en día un atractivo de gran valor desde el punto de vista turístico. Caibarién fue una de las primeras ciudades en tener un ferrocarril en 1851 y una de las primeras también en disfrutar de los beneficios que esto traía consigo. Las 8 locomotoras a vapor traídas a Cuba desde el siglo pasado hoy en día forman parte del museo que se encuentra en el CAI Marcelo Salado, de las cuales 4 se destinaron a formar parte de las instalaciones del propio museo y otras 4 deben mantenerse como material rodante. En la actualidad ofrece una opción turística, que incluye un recorrido desde este lugar hasta la Finca "La Cabaña". Para esto se emplea una locomotora con su alijo, un coche abierto con asientos para los turistas.

7. Museo del Azúcar: Central "Marcelo Salado Lastra": Su fundación se estima poco antes de 1850, se considera uno de los más antiguos de la jurisdicción de Remedios, siendo su propietario Santiago Lapeyre. Fue incendiado por las fuerzas mambisas en 1875 llevando la dotación esclava a las filas insurrectas, reanudando su molienda en la zafra del año 82-83. Para el año 1891 se le otorga la categoría de central y por el año 1898 los dueños comienzan a dotar a la industria de nuevas técnicas, entonces la palabra de orden entre sus trabajadores era "reformas" porque se comentaban unos a otros que se iban a hacer reformas en el central, tanto fue el uso de esta palabra que los dueños decidieron llamarlo "Reformas".

En el año 1961 se nacionaliza y se nombra CAI Marcelo Salado Lastra. En la actualidad el Central Marcelo Salado Lastra sigue prestando servicios al turismo en especial a visitantes de la Cayería norte de Villa Clara.

8. Hotel Comercio: Magnífico hotel que llegó a ser uno de los más confortables de la República, ya que contaba con amplias e higiénicas habitaciones con baños individuales. De fachada ecléctica fue construido por Braulio. F. Cima, en la primera década del siglo XX. Se localiza en una de las calles más céntricas del casco histórico. Este edificio cuenta con un alto valor Histórico y Arquitectónico. Actualmente se encuentra en un estado de 
deterioro total.

Ubicado en calle 6 \# 701 entre Ave 7 y Ave 9. Constaba inicialmente con 3 plantas con altura de 15 metros de mampostería y techo de hormigón. Portal de granito, descubierto excepto en la portada principal que la cubre una terraza de hormigón que en su elemento soportante tiene un acceso a la calle enmarcada por columnas que se apoyan en un sócalo $\mathrm{y}$ quedan vanos libres por ambos lados del portal $\mathrm{y}$ hacia la calle, las ventanas de la primera planta instaladas son persianas de hojas chichas tipo francés, balcones individuales en 2 da planta apoyadas en modillones que forman volutas, parados. Pilastras entre ventanas de 1era y 2da planta, desde la cenefa hasta el piso, sobre este la cornisa, apoyada en estos balcones individuales de 3era planta. Rematados en pretil.

9. Hotel Internacional: Actualmente Cabaret Las Ruinas (estado de remodelación como centro recreativo, explotado por el Grupo Extrahotelero PALMARES). Ubicado en calle 6 entre ave 17 y ave 15, frente a la antigua tabaquería. Fue la sede del gobierno interventor norteamericano en 1989, 2 do hotel del pueblo. Constaba con 3 plantas y una altura de 25 metros. Construido de sillones, maderas preciosas y tejas criollas, tenía portal de lajas, con columnas formando arcajas de medio punto. Balcones de segunda planta independientes. Escaleras con balaustres torneados de madera. Cornisa y pretil. Fue declarado en derrumbe y demolida sus plantas altas. Quedan solo los paramentos de primera planta.

Construido como Hotel Internacional este edificio goza con un indudable valor histórico y arquitectónico, fue levantado en el siglo XIX y además de reunir atributos que lo hicieron representativo del estilo Neoclásico, estaba enteramente fabricado con bloques de sillería, materiales que hasta nuestros días es prácticamente desconocido su uso en la región norte de Villa clara, lo que denota el poder económico de los inversionistas.

10. Hotel Unión: Es el primer hotel del pueblo cercano a los puertos y a la aduana. Ubicado en calle 4 \# 909 \% Ave 11 y Ave 9, al lado del antiguo Museo Municipal María Escobar Laredo. Tiene portal con columnas cuadradas. Patio claustrado. Los cuartos del frente tienen balcón corrido con baranda metálica. Paredes de mampuesto, segunda planta de madera. Techo de madera y tejas. El techo del hall de la planta alta tapizado con tabloncillo quizás encubre un harmesuelo.

Fundado en plena colonia antes de las guerras por nuestra independencia nacional. Una fonda o posada, nombrada La Marina, que tuvo su origen por el año 1858, pudo ser el antecesor del hotel, aunque nada lo atestigua con certeza. Se hospedaron personalidades reconocidas como José Raúl Capablanca. En su restaurante se ofertaban comidas francesas, inglesas, española e italiana, así como la especialidad de la casa, comida a bases de mariscos. Actualmente solo quedan las ruinas del antiguo hotel.

\section{Culinaria tradicional.}

Caibarién es conocida en por su rica y exquisita culinaria, la cual tiene sus primeros orígenes en el famoso y legendario Hotel España (desaparecido por completo en la actualidad) y donde su plato más típico resultó de una pura casualidad cuando un viajero 
llegó después de que todos los huéspedes ya habían pasado por el restaurante. El viajero preguntó entonces como se llamaba aquella comida a lo que el cocinero respondió que "Salsa da Perro". Este plato alcanzó fama internacional, además de prepararse en otras fondas de la zona portuaria, como es el también conocido Hotel Unión.

\section{Estado actual del Patrimonio de la Ciudad de Caibarién.}

En el momento actual el patrimonio tangible de la Ciudad de Caibarién se encuentra en un estado crítico de deterioro, la mayor parte de estas edificaciones necesitan una reparación capital por su acumulado descuido, además de convertirlas en espacios utilizables por la población de Caibarién y sus visitantes. Se realizan en la actualidad obras constructivas por el Ministerio de Turismo en el antiguo Liceo con en el objetivo de convertirlo en un hotel, también en el malecón se reconstruyo un local de comida rápida que funciona como un centro de recreación y disfrute a los visitantes de esta zona. Por otra parte, las fiestas tradicionales y las leyendas van perdiendo participación cada año en la vida de los ciudadanos, y por lo tanto se va perdiendo la cultura del lugar.

\section{Informe final del resultado del diagnóstico.}

De acuerdo con los resultados obtenidos podemos valorar el estado en que se encuentra la Ciudad de Caibarién para poder convertirse en el futuro en uno de los municipios de la provincia con aceptación desde el punto de vista turístico y cultural. Lo que se busca es la planificación y organización de todos estos recursos y ponerlos en función de un desarrollo perceptible del turismo local con énfasis en la gestión del patrimonio histórico - cultural. En este contexto, es importante resaltar que existe gran cantidad de sitios patrimoniales que pueden ser considerados lugares de interés para el visitante y por la cercanía al destino puede tener posibilidades de concretar una diversificación del destino Cayos de Villa Clara. Debemos ofrecer las posibilidades del conocimiento al turista y de reconocimiento del territorio cercano al destino y remarcar las condiciones históricas de la ciudad así como su acervo cultural desde su surgimiento. Terminado el estudio de los recursos patrimoniales realizado en Caibarién, se determina que la localidad posee recursos tangibles e intangibles que permiten la realización de una excursión guiada que incluya lo que realmente tiene significación histórica en la localidad.

\section{Conclusiones.}

$>$ La ciudad de Caibarién desde su fundación cuenta con elementos históricos y culturales que dieron lugar a la aparición o evolución de antecedentes turísticos que hoy forman parte de la misma como oferta complementaria al desarrollo del destino turístico Cayos de Villa Clara.

$>$ El procedimiento seleccionado contribuye a esclarecer y diagnosticar los sitios de carácter patrimonial y cultural que son de interés turístico en la ciudad de Caibarién, exponiendo el potencial histórico - patrimonial.

$>\mathrm{El}$ inventario de recursos realizado demuestra potencial que existe para conformar un producto turístico cultural, que contenga implícito el valor patrimonial de Caibarién. 


\section{Referencias Bibliográficas.}

Ausina Díaz, M. (2014). Propuesta de proyecto de desarrollo turístico local para la zona rural sureste del municipio de Caibarién. Trabajo de Diploma, Universidad Central "Marta Abreu" de Las Villas, Centro de Estudios Turísticos, Santa Clara.

Carvajal , Z. (2013). "Procedimiento de diagnóstico de los Recursos Turísticos Patrimoniales Tabgibles e Intangibles". Universidad Central "Marta Abreu" de Las Villas, Centro de Estudios Turísticos.

Couto, S. (2006). Qué es el desarrollo local. Universiad de Barcelona.

Domínguez Junco, O., Rodríguez Crespo, G., \& Fadul Franco, J. S. (Diciembre de 2017). Ideas generales para promover el turismo en zonas costeras. Desarrollo local con pequeñas empresas. Agroecosistemas, Vol.5(No.2).

Estevez, I. G. (2006). Diagnóstico para la Puesta en Valor Turístico del Patrimonio Histórico Cultural de la Ciudad de Caibarién. Tesis de grado, Universidad Central" Marta Abreu” de Las Villas., Facultad Ciencias Sociales., Santa Clara.

(s.f.). Inventario de Construcciones Conmemorativas del Ministerio de Cultura. Museo Municipal María Escobar Laredo de Caibarién, Dirección de Patrimonio.

Manente, M. (2014). Gestión de destinos y antecedentes económicos: definición y supervisión de destinos turísticos locales. CISET- Universidad de Venecia.

Morangues, D. (2006). "Turismo, Cultura y Desarrollo" en Organización de Estados Iberoamericanos para la Educación, la Ciencia y la Cultura.

Osácar, E. (2003). Master en Gestión Turística para el Desarrollo Local y Regional. Universidad de Barcelona.

Pérez, F. (9 de Noviembre de 2013). Caibarién y Remedios hacia un desarrollo local sostenible. Vanguardia.

Quintero, M., \& Gallardo, L. (2018). RELAYC. Recuperado el abril de 20 de 2018, de http://www.redalyc.org/articulo.oa?id=54315493005

Roca, P. (2014). Desarrollo local y turismo responsable.

UNESCO. (2001). "Declaración Universal de la UNESCO sobre la Diversidad Cultural". Portal de la Cultura de América Latina y el Caribe.

Yibo, Y. (2009). Procedimiento para el diagnóstico de valores culturales tangibles e intangibles, en el destino turístico de la ciudad de Zibo. Tesis Maestría, Universidad Central "Marta Abreu" de Las Villas, Centro de Estudios Turísticos, Santa Clara. 


\section{Para citar el artículo indexado.}

Rojas A., Abreu D. \& Abreu D. (2019) Análisis de recursos patrimoniales como fuente de productos turísticos en Caibarién. Revista electrónica Explorador Digital 3(2), 26-35. Recuperado desde:

http://cienciadigital.org/revistacienciadigital2/index.php/exploradordigital/article/view/417/9 $\underline{50}$

\section{Ciencia \\ Digital \\ Editorial}

El artículo que se publica es de exclusiva responsabilidad de los autores y no necesariamente reflejan el pensamiento de la Revista Explorador Digital.

El articulo queda en propiedad de la revista y, por tanto, su publicación parcial y/o total en otro medio tiene que ser autorizado por el director o editor de la Revista Explorador Digital.
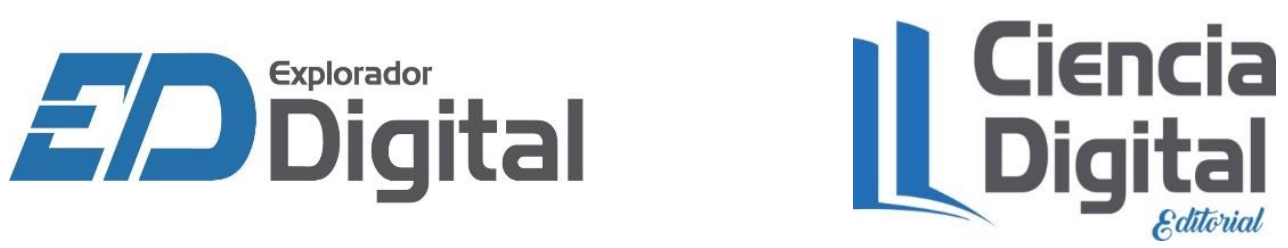